\title{
BLOOD VOLUME AND GIRGULATION TIME IN CHILDREN
}

\author{
BY \\ H. SECKEL, M.D., \\ Late of the University Children's Clinic, Cologne.
}

This paper is based mainly on the results of the author's own research work on blood volume and circulation time in cases of normal and sick children. The following methods were used:-

1. The colorimetric method for determining the circulating plasma volume, and the haematocrit method for estimating the volume of the total circulating blood; and

2. The histamine rash method for estimating the minimum circulation time of the blood.

By means of these two methods there is determined only that portion of the total blood volume which is in rapid circulation, the other part, the so-called stored or depôt blood, which is moving slowly or is almost stationary, being neglected. The organs which may act as blood depôts are the spleen, the liver, the intestines, the sub-papillary plexus of the skin and possibly the muscles. The greater part of the capillary system of these organs is quite extensive enough to supply stored-up blood as and when required to the more rapid circulation or alternatively, withdraw rapidly circulating blood and store it. This action is regulated by the autonomic nervous system. The circulating blood volume as determined by the above methods is not absolutely fixed in quantity but changes within wide limits, according to the physiological or pathological conditions under which it is measured. At the same time the stored-up blood varies in the contrary direction, provided that the total volume of blood is not affected by external losses. In the latter case, the organs containing the stored-up blood strive to make good the loss of circulating blood by sending blood into the circulatory system.

\section{Observations on healthy infants and children.}

The amount of the circulating blood volume under normal conditions in children of all ages (excepting newborn babies) amounts to $8.3( \pm 1)$ per cent. of the bodyweight, or $83( \pm 10)$ c.c. per $\mathrm{kgm}$. of bodyweight. The circulating plasma represents about 50 c.c. per kgm. of this total and the 
circulating cell volume 33 c.c. per $\mathrm{kgm}$. Relatively high values are found in the two periods of growth, i.e., between 3 and 6, or 11 and 13 years (about 90 c.c. per $\mathrm{kgm}$ ). The normal figures for adults by the same method are 75 c.c. per $\mathrm{kgm}$. of which 40 c.c. represent plasma and 35 c.c. cells. As age increases, the blood volume like other tissues becomes poorer in water, i.e., the proportion of circulating plasma volume is reduced and that of the circulating cell volume increased. (Cell plasma ratio in infants 39:61 per cent., in older children 42:58 per cent., in adults 45:55 per cent. Cf. the rise in haemoglobin and red cell figures). Chart 1 is based on these data. It can be seen how the circulating blood volume gradually increases with bodyweight and age; it is the only isolated 'organ' the increasing weight of which can be measured in vivo.

Movement, feeding and high outside temperature increase the circulating blood volume. If infants are given water to drink, there is to be observed half an hour to an hour later the so-called hydraemic reaction of the blood in the form of an increase of the circulating blood volume up to 15 per cent. of the original value with relatively higher increase of the plasma volume. The highest values to be found for the circulating blood volume under conditions of heat and bodily activity, are 11-12 per cent. of the bodyweight. If it is assumed that in such conditions the blood stores are almost empty, then the figure of 3 to 4 per cent. of the bodyweight, or 30-40 c.c. per kgm. can be deduced for the estimated size of the normally stored blood volume, that is about one-third of the circulating blood volume.

In chart 1 , the circulation time at various ages is also recorded. It increases from 14 or 15 seconds in infants to 22 seconds at the age of 15 . The average for adults is 23 to 30 seconds. What is measured by the histamine rash method is the ' minimum' circulation time of the swiftly moving particles in the axial current of the blood vessels. The average value for the circulation of all particles even the slowest moving-the ' mean' circulation time-must therefore be higher, and is estimated at about double the minimum circulating time, i.e., between 28 and 60 seconds.

The minute volume of the heart is calculated from the circulating blood volume and the mean circulation time of the blood (the ordinary methods of estimation are not applicable to children). The formula is as follows: Circulating blood volume in c.c. multiplied by 60 , and divided by the meancirculation time in seconds. The minute output of the heart therefore attains in infancy 165 c.c. per $\mathrm{kgm}$. or $\frac{1}{2}$ to $1 \frac{1}{2}$ litres, and changes slowly to the values at the end of childhood, namely 90 to 100 c.c. per $\mathrm{kgm}$. or 3 to 4 litres (adult value 70 c.c. per $\mathrm{kgm}$. or 4 to 5 litres by more direct methods). The slow decrease of the minute-output per $\mathrm{kgm}$. of bodyweight as age increases goes parallel with the decrease of the basal respiratory 
metabolism per kgm. In adults both are only about half as large as in infants.

The output per beat of the heart, found by dividing the minute volume by the pulse rate appropriate to the age, increases from 5 c.c. in the case of very young infants to 55 c.c. in the fifteen-year old child (adults 60 to 70 c.c. At the ages between 6 months and 21 years it fulfils the empiric formula $(3 \times n)+8,{ }^{6} n$ ' representing the number of completed years.

Newborn infants require a separate discussion. Here things have still a foetal character, the blood volume of the foetus being relatively enormous.

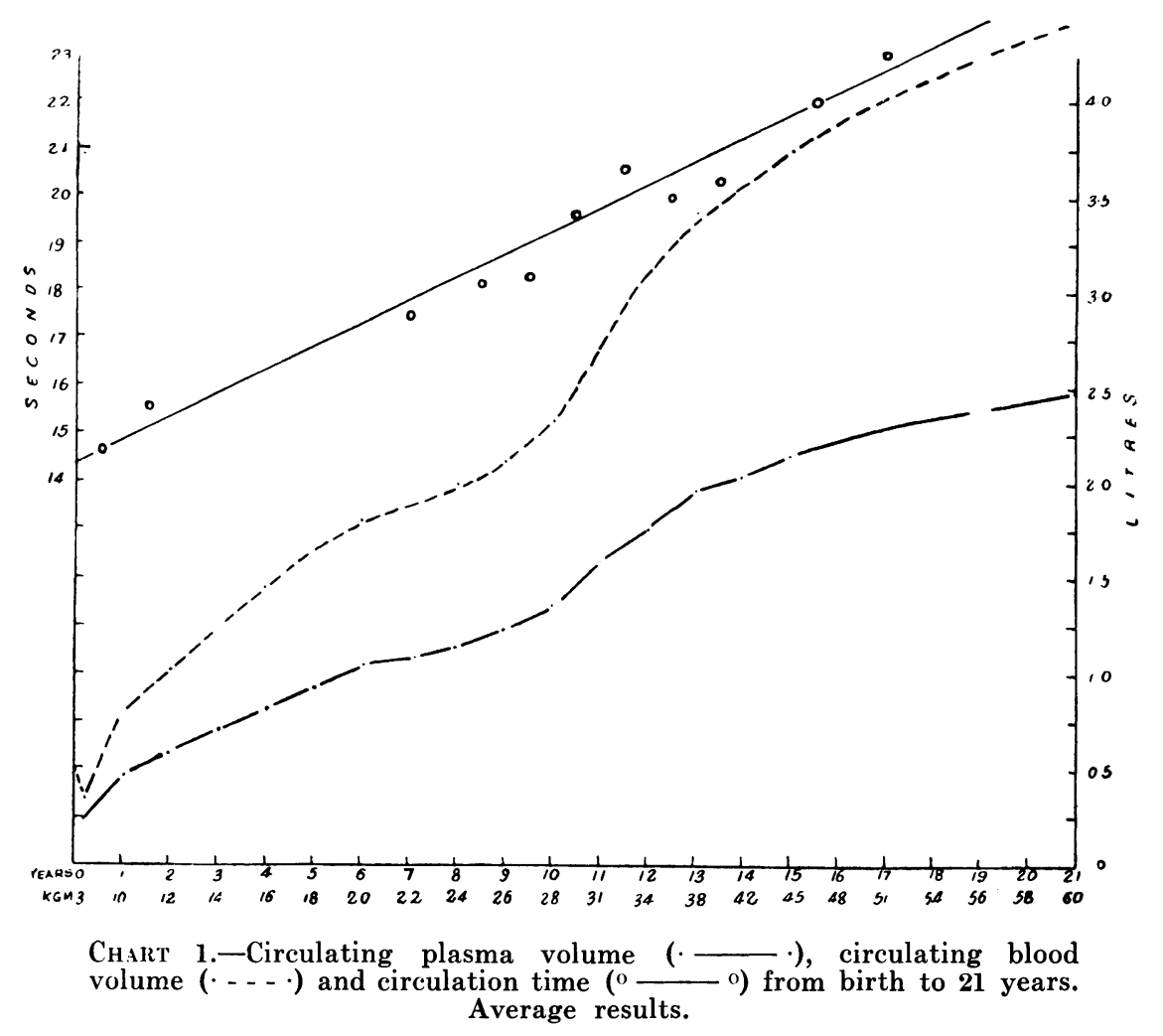

At the beginning of development it surpasses even the embryo in weight by reason of the still quicker growth of the placenta; at the same time the blood is poor in haemoglobin. Towards the end of pregnancy, however, the blood becomes rich in haemoglobin and the blood volume decreases in proportion to the embryo-weight, but never below 10 to 15 per cent. of the latter. This is the exact figure found for the circulating blood volume in newborn humans. It varies according to the time of severing the umbilical cord, i.e., according to the size of the 'postnatal blood-transfusion' (up to 100 c.c. blood) between 12 and 15 per cent. of the bodyweight or 400 to 
500 c.c. blood. The proportion of the circulating cell volume amuonts to 55 to 60 per cent. of the blood volume, according to the richness in haemoglobin and red cells of the newborn infant's blood. The circulation time of this thick blood with high cell content can be prolonged, whereby the minuteoutput of the heart is kept within reasonable limits. During first weeks after birth, the haemoglobin and red cell figures decrease (haemoglobin from about 120 to 70 per cent., red cells from about 6 to 4 millions per c.mm.) and parallel to this the circulating blood volume decreases also, especially in its cell proportion (see chart 1). It decreases from about 500 to about 350 c.c., the proportion of the circulating cell volume amounting to only 35 to 40 per cent. The destruction of this amount of blood rich in haemoglobin is the cause of icterus neonatorum and physiological anaemia during the postnatal period.

\section{Observations in sick infants and children.}

(a) Polycythaemia and anaemia.

In those types of congenital abnormalities of the heart and the larger blood vessels, in which heart and circulation partly retain their foetal character, the two sides of the circulatory system are in communication with each other, venous and arterial blood partly mix and the haemoglobin and red cell values remain high. The blood volume condition of such children reveals high figures with a relative preponderance of circulating cell volume (table 1). (The cases marked with an asterisk are here published for the first time.)

TABLE 1.

Volume of Circulating bloOd in CASES OF MORBUS coeruleus.

\begin{tabular}{|c|c|c|c|c|c|c|c|c|c|}
\hline Case & Agiv. & $\begin{array}{l}\text { Weight } \\
\text { kim. }\end{array}$ & $\begin{array}{l}\text { HaEno- } \\
\text { GI.OBIN. } \\
\text { PER CENT. }\end{array}$ & $\begin{array}{l}\text { RED CELL } \\
\text { MILIIONS. } \\
\text { PER C.MM. }\end{array}$ & $\begin{array}{l}\text { CELls } \\
\text { PER } \\
\text { CENT. }\end{array}$ & $\begin{array}{c}\text { Plasma } \\
\text { VoLUME. } \\
\text { c.C. }\end{array}$ & $\begin{array}{l}\text { Cell } \\
\text { voldua } \\
\text { C.C. }\end{array}$ & $\begin{array}{c}\text { BLOOD } \\
\text { c.c. }\end{array}$ & $\begin{array}{l}\text { VOLUNE. } \\
\text { PER CENT. } \\
\text { BODY } \\
\text { WEIGIIT. }\end{array}$ \\
\hline 3 & I $\mathrm{mth}$. & $3 \%$ & 135 & $8 \cdot 50$ & $64 \cdot 9$ & 150 & 295 & 445 & $12 \cdot 7$ \\
\hline $148^{*}$ & $3 \mathrm{yr}$. & $12 \cdot 0$ & 105 & $6 \cdot 80$ & $62 \cdot 7$ & 476 & 798 & 1274 & $10 \cdot 6$ \\
\hline $220^{*}$ & $2 \mathrm{mth}$. & 3.9 & 90 & 5.02 & $50 \cdot 6$ & 215 & 219 & 434 & $11 \cdot 3$ \\
\hline
\end{tabular}

The cases of anaemia furnish a counterpart to those of polycythaemia from the haematological point of view. Such cases in children of 2 months to 2 years have been examined. The circulating cell volume is generally speaking as much decreased as the haemoglobin value; it varies between 7 and 23 c.c. per $\mathrm{kgm}$. according to the intensity of the anaemia. The amount of circulating plasma volume shows differences. In the one group of cases-mostly constitutional types of anaemia - the plasma volume is also, although in a lesser degree, diminished (38 to 49 c.c. per $\mathrm{kgm}$ ). The total circulating blood volume is therefore considerably less (45 to 63 c.c. per 
kgm.). In the other group of cases, mostly of anaemia caused by infection, the circulating plasma volume is normal or even in a compensating degree increased ( 47 to 60 c.c. per $\mathrm{kgm}$.). The result is a normal or only slightly diminished total circulating blood volume ( 67 to 81 c.c. $\mathrm{kgm}$.). If the circulating blood volume is studied during the recovery from anaemia over a period of weeks and months (up to four examinations of one and the same child), it is possible to demonstrate the circulating cell volume increasing parallel to the haemoglobin curve and returning to normal. The circulating plasma volume in the one group also increases gradually; in the other generally decreases slowly, so that the total volume of circulating blood returns to the normal level. One example will suffice:-

Case No. 249. Infant, ten months old, with anaemia caused by an infection. Weight, 6.3 kgm. Haemoglobin, 40 per cent. Cells, 19.8 per cent. Plasma, 359 c.c. Cells, 79 c.c. Blood, 438 c.c. Eleven weeks later, after blood transfusion (100 c.c.). Weight, $7 \cdot 1 \mathrm{kgm}$. Cells, $35 \cdot 2$ per cent. Plasma, 308 c.c. Cells, 166 c.c. Blood, 474 c.c.

The circulation time of the blood appears to be shortened in cases of anaemia (the histamine rash is often not recognizable on account of the pallor). For this reason the minute volume of the heart is brought up to the normal or is even above normal, and the oxygen supply to the tissues is maintained. In recovery from cases of anaemia in early childhood, unusually high demands are made on the bone marrow, inasmuch as it has not only to replace the lost blood, but to guarantee the normal increase of blood volume during the period of recovery in proportion to the growth of the body. Energetic therapeutic steps are all the more necessary-either in the form of diet, or iron treatment, or, in severe cases, by large blood transfusions.

\section{(b) Collapse and shock.}

Collapse or shock is characterized haemodynamically as a disturbance in the blood distribution, with a striking disproportion between circulating and stored blood volume. The former is considerably reduced, the latter is proportionately increased. The blood flow is slow, the minute output of the heart is small, and the blood pressure is low. The heart and the circulatory system are insufficiently filled with blood whereas the blood stores, especially in the portal venous area, are overstocked with stagnating blood. The patient is drained of blood from the stores. Clinically he is collapsed: the skin is pale and cold, the nose peaked, the brow damp, the pulse fluttering, the heart small, the veins of the skin almost empty of blood, the liver swollen, the urinary secretion scanty. Aetiologically two groups of collapse can be distinguished: the toxic and the reflex type. In the former the small vessels of the peripheral circulation are paralyzed by poisons of chiefly an amine character. In the latter, by irritation of nervous receptors a reflex disturbs the vasomotor system. Cases of toxic collapse are mostly of a protracted nature and often end fatally. The reflex cases 
generally pass off more quickly and are seldom dangerous to life. In table 2 some examples are given from cases showing various types of collapse:-

TABLE 2.

Circulating bloOd volume in cases of collapse.

\begin{tabular}{|c|c|c|c|c|c|c|c|c|c|c|c|}
\hline $\begin{array}{l}\text { CASE } \\
\text { no. }\end{array}$ & Acie & $\begin{array}{l}\text { WEIGHT } \\
\text { KLIM. }\end{array}$ & $\begin{array}{l}\text { HAFNO- } \\
\text { GLOBIN } \\
\text { PER } \\
\text { CENT. }\end{array}$ & $\begin{array}{l}\text { RED } \\
\text { CELLL } \\
\text { MILL. } \\
\text { PLIR } \\
\text { C.M. }\end{array}$ & $\begin{array}{l}\text { AJibUMIN } \\
\text { IN } \\
\text { SLRUN } \\
\text { PER } \\
\text { CENT. }\end{array}$ & $\begin{array}{c}\text { CeLLS } \\
\text { PER } \\
\text { CENT. }\end{array}$ & $\begin{array}{l}\text { Plasina } \\
\text { Volunk } \\
\text { c.c. }\end{array}$ & $\begin{array}{c}\text { Chell } \\
\text { rolum } \\
\text { C.c. }\end{array}$ & BLOOL & $\begin{array}{l}\text { VOLUNE } \\
\text { PER } \\
\text { CENT. } \\
\text { BODY } \\
\text { WEIGHT }\end{array}$ & Cause of the COLLapse \\
\hline 69 & $\begin{array}{c}4 \\
\text { mths. }\end{array}$ & $6 \cdot 2$ & - & - & 一 & $30 \cdot 8$ & 317 & 139 & 456 & $7 \cdot 4$ & $\begin{array}{l}\text { Intussusception and } \\
\text { peritonitis }\end{array}$ \\
\hline 289 & $\begin{array}{c}3 \\
\text { mths. }\end{array}$ & $4 \cdot 69$ & 92 & $4 \cdot 78$ & $7 \cdot \overline{5}$ & $38 \cdot 5$ & 162 & 103 & 265 & $5 \cdot 6$ & $\begin{array}{l}\text { Alimentary intoxica- } \\
\text { tion. }\end{array}$ \\
\hline$-\mathbf{A}$ & & $4 \cdot 93$ & 72 & $3 \cdot 54$ & $5 \cdot 2$ & $36 \cdot 3$ & 240 & 139 & 379 & $7 \cdot 7$ & $\begin{array}{l}\text { Recovered ten days } \\
\text { later }\end{array}$ \\
\hline 291 & $\begin{array}{c}8 \frac{1}{2} \\
\text { yrs. }\end{array}$ & $2 \cdot 2 \cdot 5$ & 90 & $4 \cdot 80$ & $8 \cdot 9$ & $48 \cdot 4$ & 721 & $\begin{array}{l}677 \\
.\end{array}$ & 1398 & $6 \cdot 2$ & $\begin{array}{l}\text { Toxic diphtheria in } \\
\text { seventh week. Myo- } \\
\text { carditis with pro- } \\
\text { tracted collapse. }\end{array}$ \\
\hline$-A$ & & $22 \cdot 9$ & 82 & - & $7 \cdot 9$ & $46 \cdot 5$ & 696 & 599 & 1295 & $5 \cdot 7$ & $\begin{array}{l}\text { Fourteen days later. } \\
\text { still collapsed }\end{array}$ \\
\hline$-\mathrm{B}$ & & $23 \cdot 2$ & 80 & $3 \cdot 80$ & $7 \cdot 9$ & $41 \cdot 6$ & 920 & 664 & 1584 & $6 \cdot 8$ & Cured one month later \\
\hline 248 & $\begin{array}{l}15 \frac{1}{2} \\
\text { yrs. }\end{array}$ & $40 \cdot 3$ & 88 & $4 \cdot 32$ & - & $47 \cdot 3$ & 1801 & 1622 & 3423 & $8 \cdot \tilde{5}$ & $\begin{array}{l}\text { Orthostatic child in } \\
\text { lying position }\end{array}$ \\
\hline$-A$ & & - & - & $5 \cdot 48$ & - & $46 \cdot 2$ & 1355 & 1164 & 2519 & $6 \cdot 3$ & $\begin{array}{l}\text { After ten minutes } \\
\text { standing, collapse, } \\
\text { orthostatic albumin } \\
\text { uria }\end{array}$ \\
\hline
\end{tabular}

* By refractometer.

Cases of toxic collapse often occur in children after wounds from accidents or operation, and also from severe burns. Both are caused by histamine-like poisons, which also bring about the fever. There are often other causes also mentioned later which disturb the circulation like collapse, e.g., after operations on intussusception, through the absorption of intestinal poisons into the blood, the simultaneous narcosis, reflex shock from the peritoneum, etc. An example of an infant with intussusception and peritonitis is to be seen in table 2. The circulating blood volume is only slightly diminished, but it must be remembered that the child had a high degree of fever and that fever as such increases the blood volume. The scientific basis for subcutaneous or intravenous infusions especially in the form of constant drip infusions for such cases is clearly demonstrated.

Much investigation has been carried out in the cause of toxic collapse in alimentary intoxication of infants. The clinical appearance is recog- 
nizable at once. For some time the attention of certain paediatricians has been attracted by the slowing down and gradual disappearance of the first heart sound and the noticeable small heart shadows in the x-ray photograph. Both these factors have been explained by measuring the circulation volume in the case of toxic infants (see table 2). The circulating blood volume is much decreased and the blood thickens at the same time. As a consequence, the circulation time is greatly prolonged, the heart receives too little blood per time unit, contracts in proportion and propels its tiny output with weak systolic contractions. Besides the heart, the skin and the central nervous system also receive too little blood; vomiting and periods of unconsciousness are increased by anaemia of the brain. A great deal of the blood is stored in the depôts. In the example given, more than 100 c.c., i.e. about a quarter of the normal circulating blood volume of this child, is stored in this way. The depôts are chiefly the lungs and the portal venous area, as can be deduced from the state of the chest, the swelling of the liver and the inflation of the abdomen. The inadequate blood circulation in the intestines and liver encourages, in the manner of a vicious circle, the re-absorption of shockproducing poisons from the bowel into, the blood causing the alimentary intoxication. Therapy has always taken this into account by giving subcutaneous or intravenous infusions, stimulants and hot baths.

The last big group of cases of toxic collapse is that in which collapse is caused by acute infectious diseases such as diphtheria, scarlet fever, dysentery and typhoid, as well as in the crisis of lobar pneumonia. In these cases, the circulatory disturbances which are not primarily caused by a failure of the heart have been the subject of original observations by the author. Admittedly, very often a combination of toxic collapse and heart failure due to myocarditis is found as in the example of post-diphtheritic circulatory disturbance in table 2. Two of three investigations were made here during the developing collapse. The circulating blood volume was in both examinations greatly diminished, in the first case with simultaneous thickening of the blood, in the second case after some hydraemia. This seems to indicate the first stage of recovery from collapse, for the same was observed in the case of an infant with alimentary intoxication. At the third investigation of the diphtheritic child during convalescence the circulating blood volume was 200 to 300 c.c. greater than during the collapse. Admittedly, it had not yet reached the normal figure. Opinion has traced circulatory disturbance of this kind back to a toxic paralysis of the vasomotor nerve centres. Yet tests on diphtheria-poisoned animals have proved that the vasomotor centres can be excited normally by reflex action even shortly before death and histologically they are intact in children dying from diphtheria. It must therefore be assumed that the diphtheria toxin and the other infectious poisons attack the peripheral circulation directly, and first the vessels of the liver and bowels. The treatment is the same as in the other forms of toxic collapse, but when myocarditis is present great care must be taken to avoid overloading the circulation and abruptly raising the blood pressure. 
Reflex collapse can be brought about by irritation of the various nervous receptors. The irritation reaches the vasomotor centres and from here passes on to attack the vasodilatators and constrictors always in the same way, the tone of both being changed, resulting in a dilatation of the vessels especially in the portal venous area. A reflex collapse can also be caused by excitement of the ordinary sensory nerves, that is to say by severe pain. This is probably what happens in the case of traumatic shock, leading often to fainting. It occurs also as a result of irritation of the peritoneum, e.g. a blow on the abdomen, laparotomy, etc., and in principle is represented by the Goltz tapping test.

The majority of the cases of reflex collapse are caused by irritation of the sensory nerves. For example, a feeling of nausea can be caused by an intolerable smell or taste, vomiting may begin and acute collapse can follow. The principal receptor for bringing on reflex collapse is the compensatory organ of the aural labyrinth. The distressing condition to which seasickness can soon reduce even a healthy and robust person is well known. Also the motion of a train, motor car and aeroplane can lead to similar reactions. Likewise the same effect is found in some children after riding on a roundabout, or on the swing.

The most frequent and important of the forms of statically-caused reflex collapse in childhood is a group which is considered under the general name of ' orthostatic vasoneurosis' or ' orthostatism.' Mostly these are cases of disproportionately-grown, apparently anaemic neuropathic children between the ages of five and fifteen, who in extreme cases have a seasick-feeling merely from standing up after lying down, or after standing for only a short time. The face becomes pale and damp, the pulse small and frequent, and yawning, nausea, vomiting, dark spots before the eyes and giddiness appear. Suddenly the child falls down in a faint. After a few minutes in a horizontal position recovery takes place. The examination of the circulation in this condition shows the classic type of collapse: the blood pressure is low, the arm veins are poorly filled, the circulating blood volume has decreased by 25 per cent. of what it was when lying (see table 2), the circulation time has lengthened, the heart is poorly supplied and small, the brain practically without blood. Several hundred c.c. of blood stagnate in the depôts especially in the sub-papillary plexus of the legs (the calves look livid), and in the abdomen. Admittedly, among these the kidneys need special mention. During the collapse while standing these organs-as also the heart and the brain-are insufficiently supplied with blood and react because of their sensitivity to lack of oxygen, within a short time presenting typical functional changes, namely, oliguria and albuminuria.

Thus an explanation can be offered for the much-discussed orthostatic albuminuria. The tracing of this from orthostatic circulation collapse and the consequent anaemia of the kidney is supported by the following results of the writer's researches:-

After one hour's diathermy of the kidney region, both in short-period attempts to stand as also in whole-day standing up, a strong and occasionally 
complete suppression of the albumin secretion takes place as a result of attracting blood to the kidneys. The same observation has been made simultaneously by other writers. Orthostatic albuminuria is not necessarily a concomitant of orthostatic collapse, but is seldom absent in severe cases. In slight cases of orthostatic vasoneurosis - for not all cases are as severe as the one above described-the albumin secretion is often missed.

\section{(c) Pneumonia in early childhood.}

The fate of the infant or young child with pneumonia depends mainly less upon the local process in the lungs as on the reaction of the circulatory system to the pulmonary disturbance and the intoxication of the infective process. Attention must therefore particularly be paid to the condition of the heart and the peripheral circulation in cases of pneumonia among young children. The first question at the bedside of a pneumonic infant is 'Is the circulation compensated or de-compensated ?' A convenient indicator is the colour of the child's skin. If the skin, especially in the face and at the extremities appears rosy, pale red, or even highly flushed, then there is a good reaction to the fever, pointing to compensation. Decompensation is present when a distinct cyanotic, blue, grey-blue, or pale grey hue is seen, or when a waxlike paleness is present, with only a faint hint of red or blue mixed in it. From the purely clinical point of view three types of pneumonia can be distinguished, the red, the blue and the pallid type. The state of the circulation in these three types has been investigated and an attempt made to relate this to the state of the lungs, the degree of dyspnoea and to the general state of the child. The writer's experience is limited to twelve children most of whom had whooping cough. The results of research into the state of the circulating blood volume in these three types will first be recorded.

TABLE 3.

Circulating blood-volume in infant pNeumonia.

1. RED TYPe (average of five experiments) Circ. plasma 6.0 per cent.

Circ. blood volume $9 \cdot 2$ per cent. of body weight.

2. BLUE TYPE (average of six experiments)

Circ. plasma $4 \cdot 5$ per cent.

Circ. blood volume $7 \cdot 3$ per cent. of body weight.

3. Pallid type (average of five experiments)

Circ. plasma $6 \cdot 1$ per cent.

Circ. blood volume $10 \cdot 0$ per cent. of body weight.

1. In the red type of pneumonia in young children the circulating blood volume is found to be increased as compared with the average and individual normal levels. It is a typical fever reaction, which is found also in non-pneumonic infections. It is comparable with the febrile increase of the basal metabolism. Actual circulatory disturbances are not present. Dyspnoea is slight, the general state of health not greatly affected. The lung condition is generally localized, the course of the illness proceeds slowly, the prognosis is favourable.

2. In the blue type of pneumonia the circulating blood volume is reduced, which, in view of the fever, is specially noticeable. The subpapillary plexus of the skin swallows up much blood, the skin cools as a result of slowness of blood, the liver is swollen, the abdomen distended, the 
blood pressure is low, the pulse rate high, the heart dilated on the right side and the lungs engorged with blood. This is a so-called collapse-decompensation of the circulation. The dyspnoea is much more marked than in the ' red' cases, the muscles often atonic, listlessness is pronounced, with alternating apathy and restlessness. In the lungs is generally found a widespread pneumonia, accompanied by bronchiolitis. The course of the disease is swifter, the prognosis generally bad.

3. The pallid type of infant pneumonia is accompanied by an increase of the circulating blood volume. The pallid skin of the child does not feel cool, it is hardly cyanotic, the liver is not large, the abdomen not uniformly distended. Pulse and respiration rates are high, increasing during fits, and muscle tone is absent. An enormous quantity of blood is (with increasing speed ?) pumped through; the retentive ability of the depôts seems nil, the heart is overburdened and gives out. Most of these pallid cases have the appearance of bronchiolitis with changing areas of pneumonia. The course of the illness is often very rapid, the prognosis very unfavourable.

In spite of the small number of the investigations they do appear to give indications for the general lines of treatment of the circulatory system in pneumonia among young children. The ' red' or compensated type of pneumonia naturally needs no such treatment. In the 'blue' type measures must be taken to increase the circulation blood volume and to empty the depôts, thereby relieving the right side of the heart.

The following can be recommended: (1) warm applications, hot baths, etc.; (2) stimulation by caffein, camphor preparations. adrenaline, etc.; (3) small venesections, about 30 to 40 c.c. (repeatedly if necessary). Concentrated and bulky food must be avoided and the child must not sit up or be carried about unnecessarily.

In the 'pallid' type the following general indications can be recommended:-(1) Sedatives (chloral hydrate, codein, etc.): (2) digitalis or stronhantin; (3) large venesections, either bloodless in the skin (mustard bandage for a few minutes) or abstracting blood by puncture, venesection or arteriotomv (about 100 c.c.). The above-mentioned excitants and the overfilling of the bowel with liquids must be avoided. Care must be taken to provide plenty of fresh air treatment, routine sedatives and if necessary oxygen inhalation (ten minutes an hour) in all forms of pneumonia.

\section{(d) Hyperthyroidism and Hypothyroidism.}

In hyperthyroid children the circulating blood volume is generally increased. The circulation time of the blood volume is highly increased, so that the minute volume of the heart reaches high figures. The opposite is the case in hypothyroidism and children with excessive adipose tissue.

\section{REFERENGES.}

The details upon which this review is based are contained in the following original papers by the writer :-

Jahrb. f. Kinderh., Berlin, 1929, CXXVI, 83; ibid., 1930, CXXVII, 137; loc. cit., 149; ibid., 1931, CXXXI, 87; ibid., 1932, CXXXVI, 33; loc. cit., 220; ibid., 1932, CXXXVII, 51; ibid., 1933, CXXXVIII, 56.

Klin. Wchnschr., Berlin, 1930, IX, 441.

Monatsschr. f. Kinderh., Berlin, 1930, LII, 424.

Ztschr. f. ärztl. Fortbild., Jena, 1933, XXX, 491. 